\title{
Convolutive deconvolutive voltammetry of charge transfer complexes of 4,4'-bipyridine with benzoquinone derivatives
}

\author{
A.A. Al-Owais1, I.S. El-Hallag2 and E.H. El-Mossalamy3 \\ ${ }^{1}$ Chemistry Department, Faculty of Science, King Saud University, Reyad ,Sa \\ ${ }^{2}$ Chemistry Department, Faculty of Science, Tanta University, Tanta, Egypt \\ ${ }^{3}$ Chemistry Department, Faculty of Science, Benha University, Benha, Egypt
}

https://doi.org/10.14447/jnmes.v24i3.a07

Received: April 20-2021

Accepted: July 8-2021

\section{Keywords: \\ Convolutive voltammetry, deconvolutive voltammetry, Chronoamperometry, SEM, TEM}

\begin{abstract}
Convolutive, deconvolutive cyclic voltammetric, digital simulation, chronoamperometric, scanning electron microscopy (SEM) and transmission electron microscopy (TEM) were used for clarifying the characterization of charge transfer complex (CT) of 4,4'-bipyridine with benzoquinone derivatives. These studies were achieved at a gold electrode in TBAPL/CH2Cl2. The kind of the electrode reaction and the kinetic parameters of the CT complex under study were calculated and explained via the above methods, then confirmed via digital simulation. SEM and TEM were performed for characterization of the structural morphology of the presented complex as well as showing the nanostructured of the complex.
\end{abstract}

\section{INTRODUCTION}

Literature survey revealed that the complexes of bipyridine absorb strongly in the region of the visible spectra. The CT complexes were characterized via from six-coordinated, octahedral structures and two enantiomers. These and other homoleptic complexes of tris-2,2'-bipy of several transition metals are electroactive.1-3 One of the important studied and extensively used in the area of electrocatalysis, photocatalysis and photoelectrochemical cells are CT complex of Tris $\left(2,2^{\prime}-\right.$ bipyridine) ruthenium(II) ([Ru- (bpy)3]2+).4-6 The good merger of redox properties, chemical stability and excited reactiveness state has interested engaged much consideration of many research units. Literature survey revealed that the electrochemistry study on this complex are confined within limits only in solution and at electrodes modified chemical.57 The electrochemical behavior of ruthenium (II)/polypyridyl complexes have been the issuable of several investigations.8-14 An adequate method of changing the properties of CT complex is to adapt the bipyridine ligand by orientation the electron-withdrawing or electron-donating substituents in various positions.1515,16 4,4-Bipyridine appertain to an valuable kind of compounds with ample utilization in various areas and since the creation of CT substances produce opportunity to enhance the physical and chemical properties of different donors.16 17,18 4,4'Bipyridine appertain to an valuable kind of compounds with ample utilization in various fields and since the creation of CT substances produce opportunity to enhance the physical and chemical properties of different donors, so charge transfer substances of 4,4'-bipyridine (Bpy) with 2,3-dichloro-5,6dicyano-1,4/-benzoquinone (DDQ), 2,5-dichloro-3,6dihydroxy-1,4-benzoquinone [chloranilic acid] (CHA) and 2,3,5,6-tetrachloro-1,4'-benzoquinone [choloranil] (CHL) was observed.

Bipyridine is an arometic heterocyclic substance presenting vital class of substances which retain a system of $\pi$ and nelectrons. Paraquat (1,1/- dimethyl - 4,4/ - bypiridilium ion), also known as methyl viologen gave many utilizations such as electron transfer hindrance, a redox indicator in analytical systems and monomers in polymer creation. 17,18

The IR and 1H NMR analysis show that a charge transfer combined with a proton motion from acceptor to donor followed by intramolecular hydrogen bonding.19 The complexes of paraquat (1,1'-dimethyl-4,4'-bipyri-dinium dichloride) and chloranil with phenylhydrazones examined spectrophotometrically, and CT spectra, thermodynamic parameters and formation constants of the complexes was recorded.20 No data record has arose in the literature including CT complexes of 4,4'-bypiridine with different benzoquinone deravitives as $\pi$ acceptors.

To the best of our knowledge, literature survey revealed that up till now there is no study on the electrochemical studies of CT complex of 4,4'-bipyridine with its derivatives under consideration via convolutive voltammetry. So the present work is aimed to investigate the electrochemical properties of CT complex of 4,4'-bipyridine with derivatives of benzoquinone at working gold electrode in nonaqeous media. Also, the work presented here indicates the extraction of the electrochemical parameters of the investigated compound via various voltammetric techniques and digital simulattion. SEM and TEM were used for exhibition the morphology of CT complex of 4,4'-bipyridine with benzoquinone derivatives.

\section{EXPERIMENTAL}

\subsection{Materials}

DDQ and 4,4'-Bipyridine were obtained and supplied from Aldrich Chemical Co. The solvents used in this article were of spectral pure grade.

\subsection{Synthesis of the solid CT complexes}

Preparation of 1:1 solid charge transfer complex was carried out by mixing of 4,4 '-bipyridine $(3.0 \mathrm{mmol})$ with acceptor DDQ $(3.0 \mathrm{mmol})$ in ethanolic solution. The prepared solid 
of CT complex was filtered then washed numerous times with minimal quantities of ethanol and then dried.

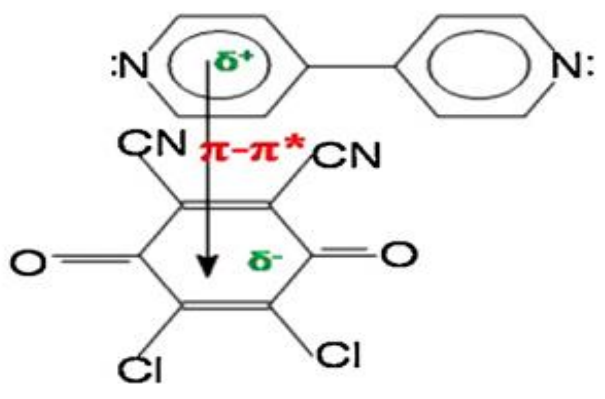

I

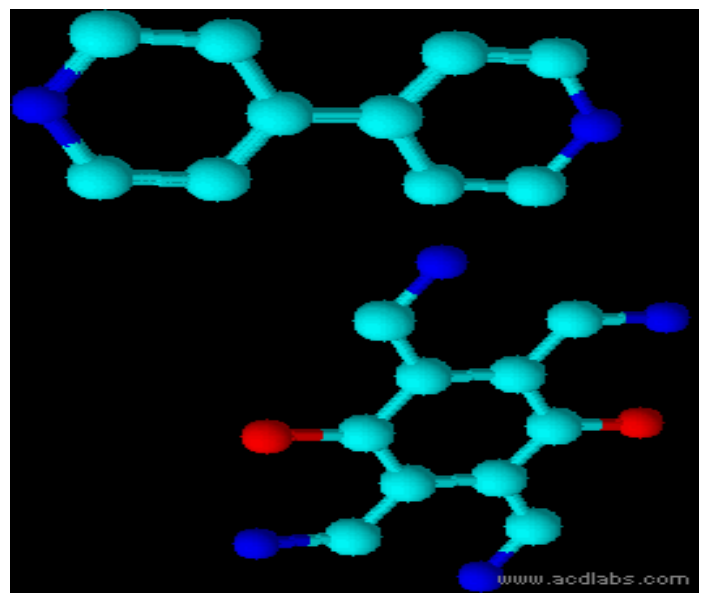

DDQ

Figure 1. The skeleton structure of CT complex of Bpy-DDQ,

\subsection{Voltammetric measurements}

Cyclic voltammetric, convolution-deconvolution transforms and chronoamperometric experiments were carried out using computerized Potentiostat Model 283 and PAR Model 175 from EG and G. The experiments were performed using arranged three electrode electrochemical cell. The gold working electrode has surface area of $6.75 \times 10-3 \mathrm{~cm} 2$, coiled platinum wire as a counter electrode and saturated $\mathrm{Ag} / \mathrm{AgCl}$ as a reference electrode. The potential was measured relative to the $\mathrm{Ag} / \mathrm{AgCl}$ reference electrode at $25 \mathrm{oC}$ and $0.1 \mathrm{~mol} / \mathrm{L}$ tetraethyl ammonium perchlorate (TEAP) as indifferent electrolyte.

Cyclic voltammetry experiments were achieved at scan rate ranging from 0.02 to $5 \mathrm{~V} / \mathrm{s}$ in $\mathrm{CH} 2 \mathrm{Cl} 2$ at $(23 \pm 2) \mathrm{oC}$.

EG \& G condesim software package was used for generation of the theoretical cyclic voltammograms via digital simulation on PC computer. Algorithms for the simulation program were codify and accomplished intinction the condesim software package provided by EG \& G. All working solutions were completely degassed with oxygen free nitrogen and a nitrogen atmosphere was keep up above the solution during the experiments.

\section{RESULTS AND DISCUSSION}

\subsection{Cyclic voltammetry of 4,4'-bipyridine with benzoquinone $\mathrm{CT}$ complex}

To examine the redox characteristics of 4,4'-bipyridine with benzoquinone, cyclic voltammetry $(\mathrm{CV})$ and convolutive voltammetry investigations were performed in methylene chloride $(\mathrm{CH} 2 \mathrm{Cl} 2)$ solution at ambient temperature $23 \pm 2$ oC with supporting electrolyte (TEAP). Fig. 1displays the cyclic voltammogram of the CT complex at sweep rate of $0.2 \mathrm{~V} . \mathrm{s}-1$ in $0.1 \mathrm{~mol} / \mathrm{LTEAP}$ at working gold electrode.

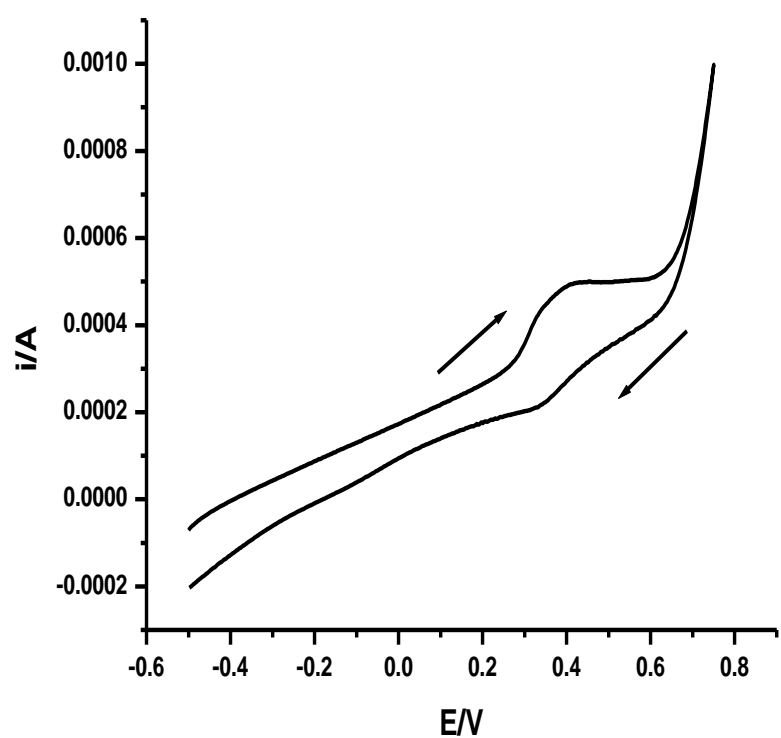

Figure 1. i-E curve of CT complex at gold electrode, sweep rate 0.2 V.s-1 and $\mathrm{T}=23^{\circ} \mathrm{C}$. The cyclic voltammogram revealed a single oxidative peak $(\mathrm{Epa}=0.451 \mathrm{~V})$ coupled with small reductive peak $(\mathrm{Epc}=0.323 \mathrm{~V})$ at $25 \mathrm{oC}$ (Figure 1). The coupled peaks describe a quasi-reversible electron transfer precedes a moderate fast chemical step (EC scheme). 21 It was obsreved that the peak isolation of CT complex $(\Delta \mathrm{Ep}=$ Epc - Epa) lie in the region $120.5-220.5 \pm 5 \mathrm{mV}$ which exceeded than the calculated value $(58 \mathrm{mV})$ for single-electron Nernstian transfer.22 This may be due to a slight sluggishness of the rate of electron transfer and further due to some solution resistance of the $\mathrm{CH} 2 \mathrm{Cl} 2$ media.23 The estimation of the formal potential (E0') was carried out from the mean values of the peak potentials position of the voltammograms and cited in Table 1. The heterogeneous rate constant (ks) was calculated via the peak separation of the voltammogram using $\Delta E p$ values versus rate constants. 24 Values of $E_{p}-E_{p / 2}$ (Table 2 ) was used for estimation of the transfer coefficient $(\alpha)$ via equation (1) and found to be $0.33 \pm 0.01$

$$
\mathrm{E}_{\mathrm{p}}-\mathrm{E}_{\mathrm{p} / 2}=48 /\left(\alpha \mathrm{n}_{\mathrm{a}}\right)
$$

where $E_{p / 2}$ is the half-peak potential i.e. the magnitude of the potential at $i_{p} / 2$ of peak current and $E_{p}$ is the oxidative peak potential. After elimination the effect of background and solution resistance, the value of $\mathrm{D}$ was calculated from relationship22,

$$
\mathrm{i}_{\mathrm{p}}=(2.99 \times 105) \mathrm{n}(\alpha \mathrm{na})^{1 / 2} \mathrm{SC}^{\text {bulk }} \mathrm{D}^{1 / 2} v^{1 / 2}
$$

where $i_{p}$ is the height of the peak current, $n$ is the number of electrons involved in electrode reaction, $\alpha$ is the symmetry coefficient and the remaining symbols have their usual definition. The value of calculated $\mathrm{D}$ was found to be $3.47 \pm$ $0.2 \times 10^{-5} \mathrm{~cm}^{2} \mathrm{~s}^{-1}$. 
Table 1. Values of the kinetic parameters obtained for 4,4 'bipyridine with benzo-quinone complex at a gold electrode at sweep rate of $0.2 \mathrm{Vs}-1$

\begin{tabular}{|l|c|c|c|c|c|}
\hline Technique & $\begin{array}{c}\mathrm{ks} \times 10^{-3} \\
\left(\mathrm{~cm} \mathrm{~s}^{-1}\right)\end{array}$ & $\mathrm{E}^{\mathrm{o}^{\prime}} / \mathrm{V}$ & $\begin{array}{c}\mathrm{D} \times 10^{5} \\
\left(\mathrm{~cm}^{2} \mathrm{~s}^{-1}\right)\end{array}$ & $\alpha$ & $\mathrm{k}_{\mathrm{c}} \mathrm{s}^{-1}$ \\
\hline Sim & 3.95 & 0.395 & 3.18 & 0.33 & 1.92 \\
\hline CV & 3.90 & 0.397 & 3.12 & 0.34 & ---- \\
\hline Conv. & ---- & ---- & $\begin{array}{c}3.25(\mathrm{a}) \\
3.29(\mathrm{~b})\end{array}$ & ---- & 1.90 \\
\hline Decon. & ---- & 0.393 & 3.27 & ---- & ---- \\
\hline CA & 3.65 & ---- & 3.65 & 0.32 & ---- \\
\hline
\end{tabular}

\subsection{Convolution-deconvolution voltammetry}

Convolutive voltammetry has been profitably useful to scrutiny of mechanism of various electrochemical processes.25-31 The diffusion coefficient of CT complex was calculated, from relationship26 (3),

$$
\mathrm{I}_{\text {lim }}=\mathrm{nFSD}^{1 / 2} \quad \mathrm{C}^{\mathrm{bulk}}
$$

where $\mathrm{I}_{\text {lim }}$ is the limiting value accomplished for I1 when the potential is forced to a sufficiently value past the peak, and the other terms has their normal meanings. Also, the diffusion coefficient was also calculated from uncomplicated and precise method via the equation29 (4),

$$
\mathrm{I}_{\text {lim }}=\mathrm{i}_{\mathrm{p}} / 3.099\left(\alpha \mathrm{n}_{\mathrm{a}} \mathrm{v}\right)_{1 / 2}
$$

where ip was defined in equation 2, and the other parameters have their known definition. The $\mathrm{I}_{1}$ convolutive voltammogram of the investigated complex under consideration was illustrated in Figure 2 which shows an obvious estrangement between the forward and reverse scan and clearly clarify the slowness of electron transport of the redox step. As shown in figure 2 the backward direction of the $\mathrm{I}_{1}$ convolution does not reach to initial value due to chemical reaction appears at longer time scales of the experiment. The values of D calculated via equations 3 and 4 are summarized in Table 1. The homogeneous chemical rate constant $\left(\mathrm{k}_{\mathrm{c}}\right)$ of the chemical step can be precisely evaluated via the kinetic convolution $\left(\mathrm{I}_{2}\right)$ at a sweep rate of $0.2 \mathrm{Vs}^{-1}$, which explored in Figure 3 and determined from the proper value of the chemical rate constant attained by putting trial value of the homogeneous chemical rate constant $\left(\mathrm{k}_{\mathrm{c}}\right)$ into the convolution calculation until $I_{2}$ returned to zero immediately after the peak. ${ }^{31}$ This is entirely a rumination of the nonappearance of the reductive species at the electrode at potentials prior the peak when the bulk concentration of this species is zero. The true $\mathrm{k}_{\mathrm{c}}$ value determined from $\mathrm{I}_{2}$ convolution was found to be $1.9 \mathrm{~s}^{-1}$ which agrees with the value used in simulated cyclic voltammograms.

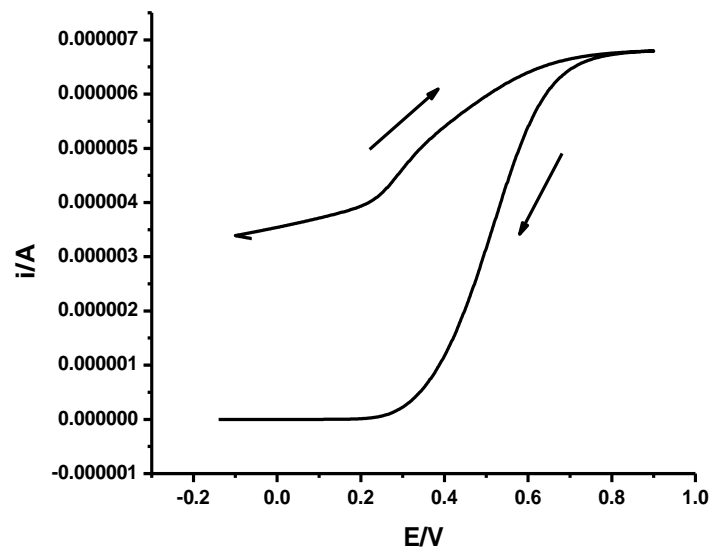

Figure 2. Convoluted current of CT complex at working gold electrode, sweep rate $0.2 \mathrm{~V} \mathrm{~s}^{-1}, \mathrm{~T}=23{ }^{\circ} \mathrm{C}$.

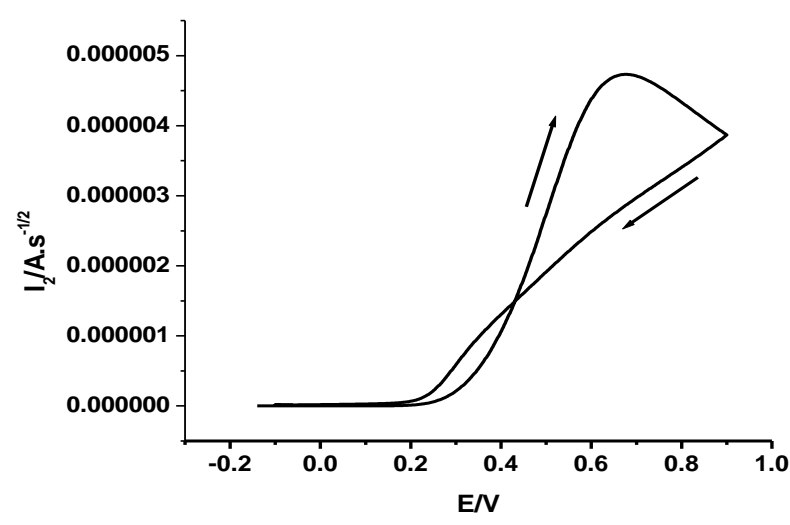

Figure 3. Kinetic convoluted current $I_{2}$ of $C T$ complex at platinum electrode, sweep rate of $0.5 \mathrm{~V} \mathrm{~s}^{-1}, \mathrm{~T}=25^{\circ} \mathrm{C}$.

The diffusion coefficient was also determined from deconvolution using equation ${ }^{28} 5$,

$$
\frac{\alpha n^{2} F^{2} v C^{\text {bulk }} \mathrm{D}^{1 / 2}}{3.367 \mathrm{RT}}
$$

where $e_{p}$ is the height of the forward peak (in Ampere) of deconvolutive voltammetry and the other symbols have their normal meanings. The magnitude of D calculated from Eq. (5) is cited in Table 1.

Also from combination between convolution and deconvolution transforms the relationship (6) was deduced:

$$
\begin{aligned}
& \mathrm{n}=\frac{\mathrm{ep} 3.367 \mathrm{RT}}{\alpha \mathrm{Fv} \mathrm{I}_{\mathrm{lim}}} \\
& \mathrm{n}=\frac{0.086 \mathrm{ep}}{\mathrm{I}_{\mathrm{lim}} \alpha v}
\end{aligned}
$$

where $\mathrm{n}$ is the number of electrons consumed in electrode reaction, and the other parameters have their usual definitions. From relationship (6) the number of electrons expended in the electrode reaction was evaluated and establish to be $1.14 \mathrm{ca}$. 1. As demonstrated the number of electrons was calculated precisely via a simple method. 
Table 2. Peak characteristics of the investigated of CT complex 4,4'-bipyridine with benzoquinone extracted from cyclic voltammetry, deconvolution voltammetry and digital simulation techniques at $0.5 \mathrm{~V} \mathrm{~s}^{-1}$.

\begin{tabular}{|l|l|l|}
\hline $\mathrm{Ep}-\mathrm{Ep} / 2 / \mathrm{mV}$ & $86(\mathrm{a})$ & $87(\mathrm{c})$ \\
\hline $\mathrm{Ep}-\mathrm{Eo} / \mathrm{mV}$ & $87(\mathrm{a})$ & $88(\mathrm{c})$ \\
\hline $\mathrm{Wp} / \mathrm{mV}$ & $126(\mathrm{~b})$ & $124(\mathrm{c})$ \\
\hline$\Delta \mathrm{ep} \mathrm{deconv./mV}$ & $84(\mathrm{~b})$ & $83(\mathrm{c})$ \\
\hline $\mathrm{epf} /$ epb (Deconv) & $1.17(\mathrm{~b})$ & $1.19(\mathrm{c})$ \\
\hline
\end{tabular}

(a) Values determined from $\mathrm{CV}$, (b) values determined from deconvolution and (c) values determined from digital simulation

\subsection{Digital simulation}

In this work, Digital simulation was achieved on PC computer via EG \& G Condesim software program. The machine was computerized in Pascal. The simulation process was accomplished using finite differences techniques. ${ }^{32,33}$ Algorithms for the simulation program were coding and enforced into the Condesim software package supplied by EG $\&$ G. A direct examination of the electrochemical parameters was achieved by creating the theoretical cyclic voltammogram of 4,4'-bipyridine with benzoquinone complex using the mean values of electrochemical parameters attained experimentally and matching it with the voltammogram recorded experimentally. Figure 4 displays a good matching between the theoretical and experimental $\mathrm{i}-\mathrm{E}$ curves at a sweep rate of $0.2 \mathrm{~V} . \mathrm{s}^{-1}$ confirming the transfer of one electron transfer precede a moderate fast chemical step.

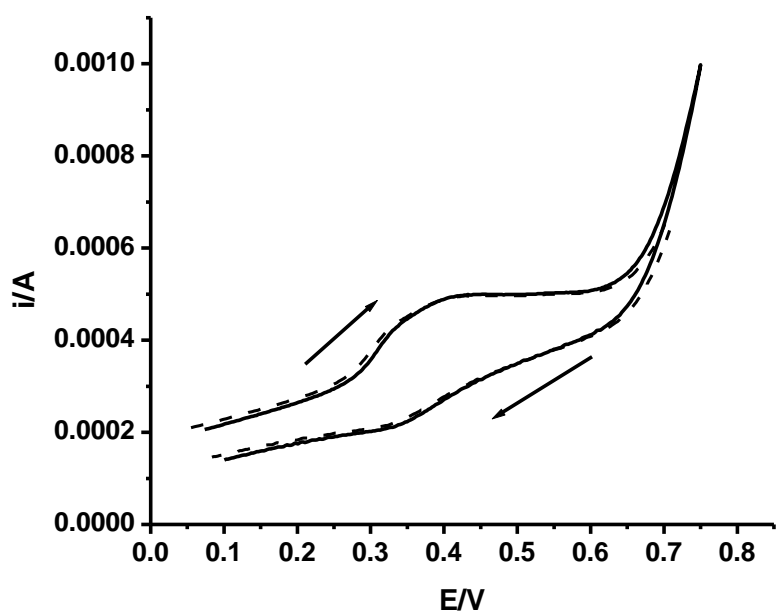

Figure 4. Agreement between experimental (- ${ }_{-}$) and theoretical curves $(\ldots \ldots \ldots)$ of $\mathrm{CT}$ complex at a sweep rate of $0.2 \mathrm{~V} \cdot \mathrm{s}^{-1}$ and $\mathrm{T}=23{ }^{\circ} \mathrm{C}$.

\subsection{Chronoamperometry of CT complex.}

Chronoamperometric experiments were achieved by stepping the potential from the initial value $(0.3 \mathrm{~V})$ where no electron transfer occurs, to a value in the region of $0.32 \mathrm{~V}$ to $0.39 \mathrm{~V}$ and the current was recorded as a function of time. Chronoamperogram of the CT complex in $0.1 \mathrm{~mol} \mathrm{~L}-1$ TBAP $/ \mathrm{CH}_{2} \mathrm{Cl}_{2}$ at a gold electrode at potential step from $\mathrm{E}_{\mathrm{i}}(0.3 \mathrm{~V})$ to $\mathrm{E}_{\mathrm{f}}(0.34 \mathrm{~V})$ is displayed in Figure 5 . The rate constant $\mathrm{k}_{\mathrm{f}}$ was calculated via equation ${ }^{30} 7$,

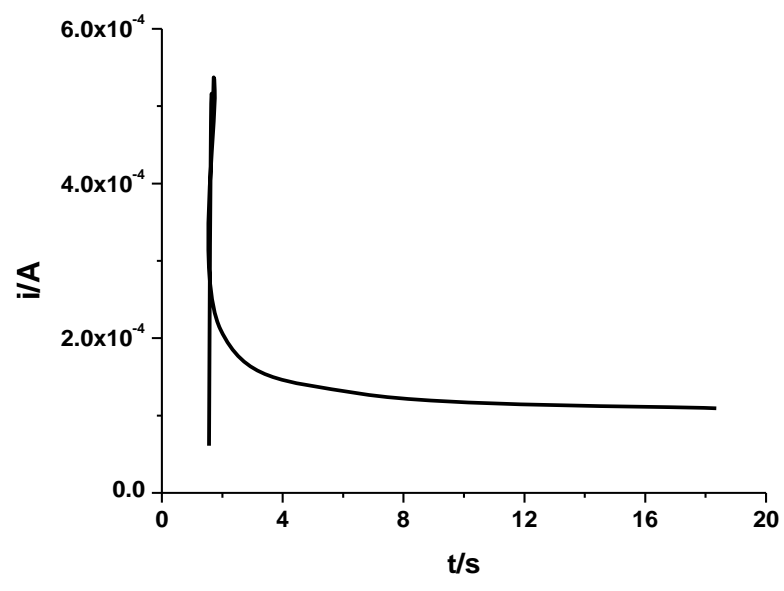

Figure 5 . i-t curve of CT complex of 4,4'-bipyridine with benzoquinone at gold electrode and at $\mathrm{T}=25^{\circ} \mathrm{C}$.

$$
\mathrm{i}(\mathrm{t})=-\beta \mathrm{I}_{1}+\mathrm{u}
$$

where $\mathrm{u}=\mathrm{nFSC} \mathrm{Culk}^{\text {bulk }} \mathrm{k}_{\mathrm{f}}$ (D) $1 / 2$ and $\beta=\mathrm{k}_{\mathrm{f}}(\mathrm{D})^{1 / 2}$. Measurements of the intercept at $\mathrm{I}_{1}=0$ and the slope of the straight line of $i(t)$ versus $I_{1}$ produce $k_{f}$ Here, the basic relation between the rate constant of the electron transfer and the potential of the electrode is considered in treatment the Butler-Volmer relationship which can be written in the equation ${ }^{28} 8$,

$$
\ln \mathrm{k}_{\mathrm{f}}=\frac{\alpha \mathrm{nF}}{\mathrm{RT}}\left(\mathrm{E}_{\mathrm{f}}-\mathrm{E} \mathrm{o}^{\prime}\right)+\ln \mathrm{k}_{\mathrm{s}}
$$

The value of $\alpha$ was computed from slope of the linear line of $\ln \mathrm{k}_{\mathrm{f}} v s$. $\left(\mathrm{E}_{\mathrm{f}}-\mathrm{E}^{\mathrm{o}^{\prime}}\right)$ and was being to be 0.32 , while value of $\mathrm{k}_{\mathrm{s}}$ was calculated at the point at which $\mathrm{E}_{\mathrm{f}}=\mathrm{E}^{\mathrm{o}^{\prime}}$ and was estimated to be $3.65 \times 10^{-3} \mathrm{~cm} \mathrm{~s}^{-1}$. Both values are adhere well with those found from the experimental and theoretical calculations used this work (Table 1).

\subsection{SEM and TEM Techniques}

The morphology of the CT complex in the present article was characterized by scanning electron microscopy (SEM) and transmission electron microscopy (TEM), due to their good resoluteness and great imaging quickness. Bpy-DDQ charge transfer complex was exam-ined under scanning electron microscope (SEM) Fig. 5 A \& B. Size dissemination and average particle radius were determined analyzing 4-6 picures, presenting accumulation of more than 2000 particles. SEM images indicates that these nanoparticles attend to accumulate to produce clusters in the region of $50 \mathrm{~nm}$ to 100 $\mathrm{nm}$. The view of Bpy-DDQ single-crystalline particles resemble to such as rectangular like structures. TEM photograph of Bpy- DDQ exhibited that $10-15 \mathrm{~nm}$ particles are spherical in the sample (Fig. 6) 


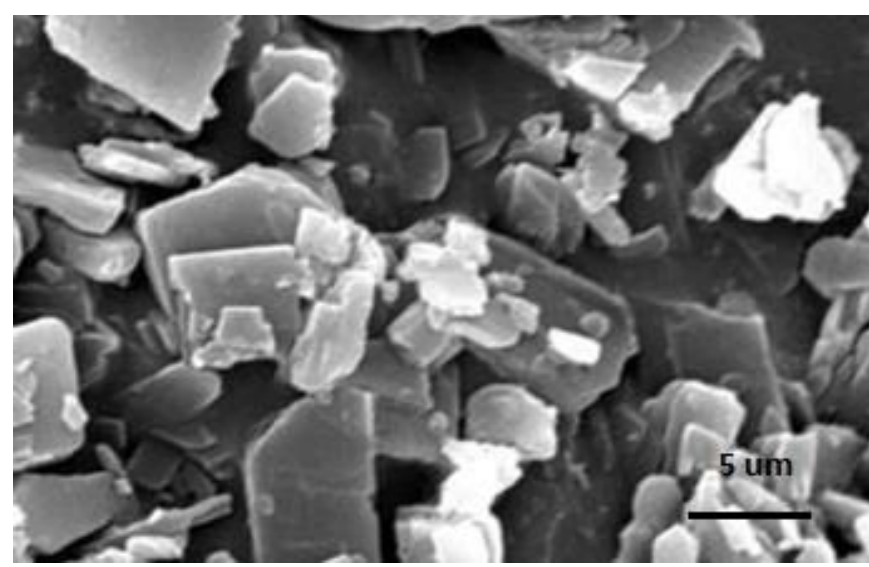

$\mathbf{A}$

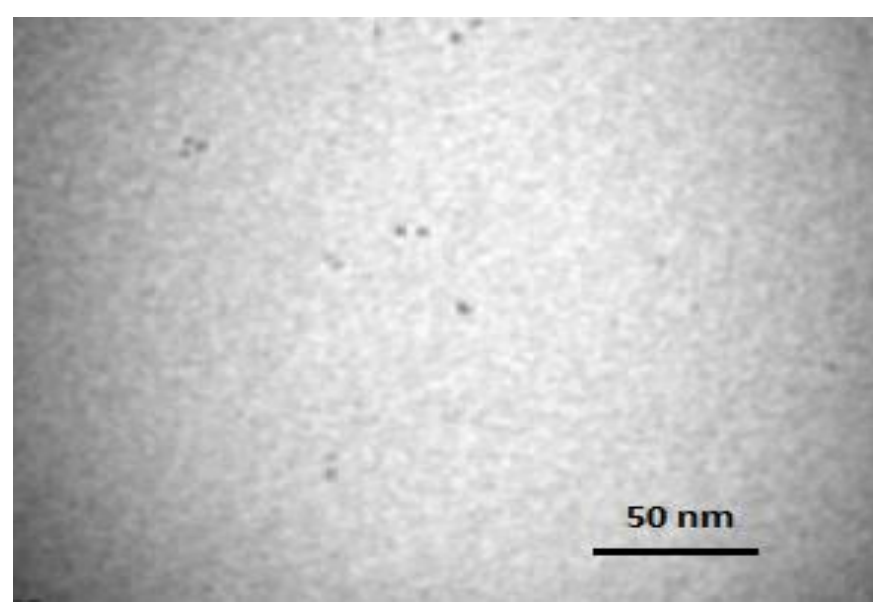

B

Fig. 6. (A) The scanning electron image (SEM) and (B) transmission electron image for Bpy-DDQ complex

\section{CONCLUSIONS}

In this article the electrochemistry of CT 4,4'-bipyridine with benzoquinone complex was explained at a working gold electrode in $0.1 \mathrm{~mol} \mathrm{~L}{ }^{-1} \mathrm{TBAP} / \mathrm{CH}_{2} \mathrm{Cl}_{2}$ solution using cyclic voltammetric, convolutive deconvolutive voltammetry and chronoamperometric experiments.The chemical and electrochemical constants of the investigated CT of 4,4'bipyridine with benzoquinone complex have been computed experimentally and verified theoretically via digital simulation software The electrode reaction was found to behave as moderate speed charge transform continued by chemical reaction step i.e., EC mechanism. Transmission electron microscopy and scanning electron microscope was used to explain and clarify the morphology of the CT compound.

\section{ACKNOWLEDGMENT}

This project was supported by King Saud University, Deanship of Scientific Research, College of Science, Research Center.

\section{REFERENCES}

[1] Göller A and Grummt U W 2000 Torsional barriers in biphenyl, 2,2'-bipyridine and 2-phenylpyridine. Chem. Phys. Lett. 321:399-405. doi: https://doi.org/10.1016/S0009-2614(00)00352-3

[2] Smith A P, Lamba J J S and Fraser C L 2002a Efficient synthesis of halomethyl-2,2'-bipyridines:4,4' bis(chloromethyl)-2,2'-bipyridine. OrgSynth 78:82. doi: https://doi.org/ 10.- 15227/ orgsyn.078.0082

[3] Smith A P, Savage S A, Love J C, and Fraser C L 2002b Syntheis of 4-, 5-, and 6-methyl-2,2'-bipyridine by a Negishi cross-coupling startegy: 5-methyl-2,2'bipyridine. Org Synth 78:51. doi: https://doi.org/10.15227/orgsyn.078.0051

[4] Kalyanasundaram K 1982 Photophysics, photochemistry and solar energy conversion with tris(bipyridyl)ruthenium(II) and its analogues. Coord Chem Rev 46:159-244. doi: https://doi.org/10.1016/0010-8545(82)85003-0

[5] Juris A, Balzani v, Barigelletti F, Campagna v, Belser P, and Von Zelewsky A 1988 Ru(II) polypyridine complexes: photophysics, photochemistry, eletrochemistry, and chemiluminescence. Coord Chem Rev 84:85-277. doi: https://doi.org/10.1016/0010$\underline{8545(88) 80032-8}$

[6] Gratzel M 1983 Energy Resources through Photochemistry and Catalysis. Academic Press, London

[7] Gobi K V, Ramaraj R 1998 Multistep one-electron photoelectrocatalytic reduction of oxygen at tris $\left(2,2^{\prime}-\right.$ bipyridine)ruthenium(II)-incorporated Nafion ${ }^{\circledR}-$ and clay-coated electrodes in the presence of macrocyclic cobalt(III) complexes. J Electroanal Chem 449:81-89. doi: https://doi.org/10.1016/S0022-0728(98)00009-6

[8] Anderson PA, Deacon GB, Haarmann KH, Keene FR, Meyer TJ, Reitsma DA, Skelton BW, Strouse GF, Thomas NC, Treadway JA, White AH (1995) Designed Synthesis of Mononuclear Tris(heteroleptic) Ruthenium Complexes Containing Bidentate Polypyridyl Ligands. Inorg Chem 34:6145-6157. doi: https://doi.org/10.1021/ic00128a028

[9] Dodsworth ES, Lever ABP (1986) Correlations between electrochemical potentials and optical charge transfer energies in ruthenium bipyridine derivatives. Chem Phys Lett 124:152. doi: https://doi.org/10.1016/00092614(86)85135-1

[10] Metcalfe RA, Dodsworth ES, Fielder SS, Stufkens DJ, Lever ABP, Pietro WJ (1996) Influence of Remote Ligand Lone Pairs on the Electronic Structure and Spectrum of Bis(bipyridine)ruthenium(II) 3,4-Diamino3',4'-diimino-3',4'-dihydrobiphenyl. Tuning by External Donors and Acceptors. Inorg Chem 35:77417750. doi: https://doi.org/10.1021/ic960232s

[11] Llanguri R, Morris JJ, Stanley WC, Bell-Loncella ET, Turner M, Boyko WJ, Bessel CA (2001) Electrochemical and spectroscopic investigations of oxime complexes of bis(bipyridyl)ruthenium(II). Inorg Chim Acta 315:53-65. doi: https://doi.org/10.1016/S0020-1693(01)00315-2

[12] Yang XJ, Janiak C, Heinze J, Drepper F, Mayer P, Piotrowski H, Klüfers P (2001) Heteroleptic 5,5'disubstituted-2,2'-bipyridine complexes of ruthenium(II): spectral, electrochemical, and structural 
investigations. Inorg Chim Acta 318:103-116. doi: https://doi.org/10.1016/S0020-1693(01)00414-5

[13] Constantino VRL, Oliveira LFC, Santos PS., Toma HE (1994) Spectroscopic and electrochemical studies on (2hydroxypicolinate)-bis(2,2'-bipyridine)ruthenium(II) and related complexes. Transit Metal Chem 19:103-107. doi: https://doi.org/10.1007/BF00166280

[14] Gorelsky SI, Dodsworth ES, Lever ABP, Vlcek AA (1998) Trends in metal-ligand orbital mixing in generic series of ruthenium N-donor ligand complexes-effect on electronic spectra and redox properties. Coord Chem Rev 174:469-494. doi: https://doi.org/10.1016/S0010$\underline{\text { 8545(98)00144-1 }}$

[15] Eskelinen E, Luukkanen S, Haukka M, Ahlgrén M, Pakkanen TA (2000) Redox and photochemical behaviour of ruthenium(II) complexes with H2dcbpy ligand (H2dcbpy = 2,2'-bipyridine-4,4'-dicarboxylic acid). J Chem Soc, Dalton Trans 2745. doi: https://doi.org/10.1039/B004751L

[16] Kinnunen TJJ, Haukka M, Nousiainen M, Patrikka A, Pakkanen TA (2001) Electron withdrawing and electron donating effects of 4,4'-bipyridine substituents on ruthenium mono(bipyridine) complexes. J Chem Soc, Dalton Trans 2649-2654. doi: https://doi.org/10.1039/B103067C

[17] Bird CL, Kuhn AT (1981) Electrochemistry of the viologens. Chem Soc Rev 10:49-82. (and refs. threin). doi: https://doi.org/10.1039/CS9811000049

[18] Kuwabar T, Takeuchi K, Nanasawa M (1998) Colormodulation by Additives for Photochromism of Cyclic Viologen Derivatives. Supermol Chem 10:121-124. doi: https://doi.org/10.1080/10610279808055403

[19] Teleb SM, Gaballa AS (2005) Preparation and spectroscopic studies on charge-transfer complexes of 2,2'-bipyridine with picric and chloranilic acids. Spectrochim Acta 62:140-145. doi: https://doi.org/10.1016/j.saa.2004.12.017

[20] Singh TC, Rao PV, Veeraiah T, Venkateswarlu G (2003) Indian J Chem 42A:1666-1670. doi: http://nopr.niscair.res.in/handle/123456789/20697

[21] El-Hallag IS, Ghoneim MM (1996) Electrochemical Investigation of N,N'-Propylene-bis(salicylideneiminato) $\mathrm{Mn}(\mathrm{III})$ in Phosphate Buffer Solutions. Monatsh Chem 127:487494. doi: https://doi.org/10.1007/BF00807073

[22] Nicholson RS, Shain I (1964) Theory of Stationary Electrode Polarography. Single Scan and Cyclic Methods Applied to Reversible, Irreversible, and Kinetic Systems. Anal Chem 36:706-723. doi: https://doi.org/10.1021/ac60210a007

[23] Gaudiello JG, Wright TC, Jones RS, Bard AJ (1985) Electrochemical reduction and reoxidation accompanied by reversible geometric isomerization. Electrochemistry of bis(dicarbonyl-.mu.-di-tert-butylphosphidorhodium). Isolation and $\mathrm{x}$-ray crystal structure of bis(tetra-nbutylammonium)bis(dicarbonyl-.mu.-di-tert-

butylphosphidorhodate). J Am Chem Soc 107:888-897. doi: https://doi.org/10.1021/ja00290a026

[24] Nichlson RS (1965) Theory and Application of Cyclic Voltammetry for Measurement of Electrode Reaction Kinetics. Anal Chem 37:1351-1355. doi: https://doi.org/10.1021/ac60230a016
[25] Imbeaux JC, Savéant JM (1973) Convolutive potential sweep voltammetry: I. Introduction. J Electroanal Chem Interf Electrochem 44:169-187. doi: https://doi.org/10.1016/S0022-0728(73)80244-X

[26] Dobson ID, Taylor N, Tipping LRH (1986). Electrochemistry, Sensor and Analysis, Elsevier, Amsterdam, pp 61-75

[27] El-Hallag IS, Ghoneim MM, Hammam E (2000) New method for the investigation of $\mathrm{CE}$ system via convolutive voltammetry combined with digital simulation. Anal Chim Acta 414:173-180. doi: https://doi.org/10.1016/S0003-2670(00)00819-9

[28] Ghoneim MM, El-Hallag IS (1999) Electrochemical Investigation of Some Ruthenium-Carborane Complexes at a Glassy Carbon Electrode. Monatsh Chem 130:525535. doi: https://doi.org/10.1007/PL00010231

[29] Oldham KB (1983) The extraction of kinetic parameters from chronoamperometric or chronocoulometric data. Anal Chem 145:9-20. doi: https://doi.org/10.1016/S0022-0728(83)80289-7

[30] El-Hallag IS, Hassanein AM, Ghoneim MM (1995) Electrochemical Study of the Hetero-Bimetallic Complex $\left[\mathrm{MeNC}(\mathrm{CO})_{2} \mathrm{Mn}(\mathrm{dppm})_{2} \mathrm{Pt}(\mathrm{H})(\mathrm{CNMe})\right]^{+} \mathrm{PF}_{6}^{-}$ at a Glassy Carbon Electrode. Monatsh Chem 126:10751085

[31] El-Daly SA, El-Hallag IS, Ebied EM, Ghoneim MM (2009) Electrochemical Studies of 1,4-Bis[2-(2-pyridyl)vinyl] Benzene and 1,4-Bis[2-(4-pyridyl) vinyl] Benzene Laser Dyes via Cyclic Voltammetry, Convolutive Voltammetry and Digital Simulation Methods. Chin J Chem 27:241-247. doi: https://doi.org/10.1002/cjoc.200990039

[32] Feldberg SW (1969) Digital simulation: a general method for solving electrochemical diffusion-kinetic problems. Electroanal Chem 3:199Feldberg SW (1969) In: Bard A J (ed) Electroanalytical chemistry, Marcel Dekker, New York

[33] Britz (1981) Digital Simulation in Electrochemistry. Springer, Berlin 